\title{
Experimental Analysis of the Vapour Compression Refrigeration System with Microchannel Condenser using R134a and R1234yf Refrigerant
}

Prakash $\mathrm{K} \mathrm{B}^{1^{*}}$, Subramaniyan $\mathrm{C}^{1}$, Chandrasekaran $\mathrm{M}^{1}$, Kalidasan $\mathrm{B}^{1}$, Amarkarthik $\mathrm{A}^{1}$, Manoj Kumar $\mathrm{P}^{2}$, Saravanakumar $\mathrm{S}^{3}$

${ }^{1}$ Department of Mechanical Engineering, Bannari Amman Institute of Technology, Sathyamangalam, Erode, Tamilnadu, India.

${ }^{2}$ Department of Mechanical Engineering, KPR Institute of Engineering and Technology, Coimbatore, Tamilnadu, India.

${ }^{3}$ Department of Mechanical Engineering, M Kumarasamy College of Engineering, Karur, Tamilnadu, India.

*Corresponding Author: kbprakash404@gmail.com

\begin{abstract}
Vapour Compression Refrigeration (VCR) system with high COP, low input power consumption and minimal exergy losses are of great research hotspot. The current research focuses on analysis of exergy and performance of vapour compression refrigeration (VCR) cycle is in a real-world application. Experiments were carried out in the VCR system using round tube condenser and microchannel condenser along with different refrigerants R134a, and R1234yf. Temperatures were varied from $+20^{\circ} \mathrm{C}$ to $5^{\circ} \mathrm{C}$ for the evaporator and $40^{\circ} \mathrm{C}$ to $50^{\circ} \mathrm{C}$ for the condenser. Among the two refrigerants, experimental results show that refrigerants operating in micro-channel condensers have COP of $6 \%$ and $4 \%$ greater higher with $5 \%$ and $3 \%$ lower exergy loss compared to the round tube condenser for R134a and R1234yf respectively. R1234yf appears to be a better equivalent for R134a, according to the findings. The efficiency defect in the condenser is the greatest and least in the evaporator for the coolants examined.
\end{abstract}

Keywords: VCR system, R134a, R1234yf, COP, Exergy. 


\section{INTRODUCTION}

The majority of residential refrigerators uses vapour compression technology, which is one of the most energy-intensive appliances in the home (Juan et al., 2020). For example, vapour compression technology accounts for roughly $17 \%$ of global energy demand. This consumption has a direct impact on the quantity and means of energy generation, resulting in an environmental imprint and worldwide economic impact (Meng Yang et al., 2019).In this context, research in this field has accelerated, focusing mostly on ways that increase the performance of vapour compression devices. One of the approach is using of alternative refrigerants to R134a and another one is using of effective heat exchanging devices like evaporator and condenser (Gaurav et al., 2018).

Refrigerants for the alternative are being explored for use in innumerable applications because R134a has a global warming effect of 100 years (Garcia et al., 2021). R134a should be phased out in the near future, according to the Kigali amendment to the Montreal Protocol in 2020. R1234yf and R1234ze (E), two GWP 1 hydrofluoroolefins (HFOs) with low GWP (IPCC, 2013), are being studied as potential R134a replacements (Martin et al, 2021).

(Akasaka et al., 2010) presented theoretical analyses to establish the direct substitution's viability of R1234yf in VCR system that use R134a, inauto mobile air conditioner. (Lee et al., 2012) explored the viability of deputize for R134a in mobile air conditioner by measuring the R1234yf drop-in performance in a basic desk analyzer. With some modifications, (Zilio et al., 2010) tested R1234yf at an orthodox R134a. (Bryson et al., 2011) explored the use of R1234yf in place of R134a in an automobile air conditioner.(Reasor et al., 2010) compared thermophysical parameters and simulated operational settings to see whetherR1234yf could be used as a direct replacement for an R134a or R410A-based on the system performance. R1234yf and additional innovative refrigerants were considered by (Lecket al., 2010) as possible replacements for different high-GWP refrigerants. (Endoh et al., 2010) experienced the system performance capacity of a chamber in air conditioner that 
had previously used R410A as refrigerant. (Okazaki et al., 2013) investigated the air conditioner performance in a room that was originally intended for R410A and was modified to use R1234yf and R32/ R1234yf mixes.

(Moles et al., 2014) studied the behavior of the VCR system by adding the additional heat exchanger in the system. (Nuns et al., 2015) studied the behavior of the R1234yf in a single VCR system with round tube condenser for variable evaporator temperature. (Yatagan baba et al., 2015) studied the behavior of VCR system with refrigerant as R1234yf using double evaporators.

(Sánchez et al., 2017) examined the energy performance analysis on the single VCR system by varying the evaporator temperature. In another study, (Navarro et al., 2019, Martin et al., 2021) examined HFO-1234yf as a direct replacement for HFC-134a in a refrigeration system. Under a variety of working situations, HFC-134a and HFO-1234yf's energy performance was compared. According to the findings from the above researchers, In an HFC-134a vapour compression system, HFO-1234yf's refrigerating effect and COP were approximately $9 \%$ and $19 \%$ lesser, respectively, than HFC-134a's.

From the above mentioned research works it is quite evident that R1234yf is the most commonly tested refrigerant for refrigeration technique. In addition VCR refrigeration systems with micro channel condenser are very attractive. The current research work aims to examine the performance of the VCR refrigeration system by replacing the existing refrigerant and the type of condenser. The author have replaced micro channel condenser with round tube condenser and $\mathrm{R} 134 \mathrm{a}$ refrigerant with R1234yf refrigerants. The performance of VCR system with micro channel condenser using R134a and R1234yf refrigerants are compared numerically in this research. 


\section{EXPERIMENTAL SETUP}

The testing in this study are conducted in a laboratory for experimental testing that includes a vapour compression system, shown in Figure 1 that works with the round tube condenser, micro channel condenser, refrigerants R134a and R1234yf.Properties of refrigerants R134a and R1234yf are shown in Table 1. A freezer reciprocating compressor with fixed speed and finned tube heat exchangers serve as evaporator and condenser coils in the system. The expansion device used for R134a and R1234yf is a thermostatic expansion valve. At rating conditions, the system does have a capacity of $400 \mathrm{~W}$ and EER values of 3.8. This was a commercially produced R134a compressor with a greater capacity.

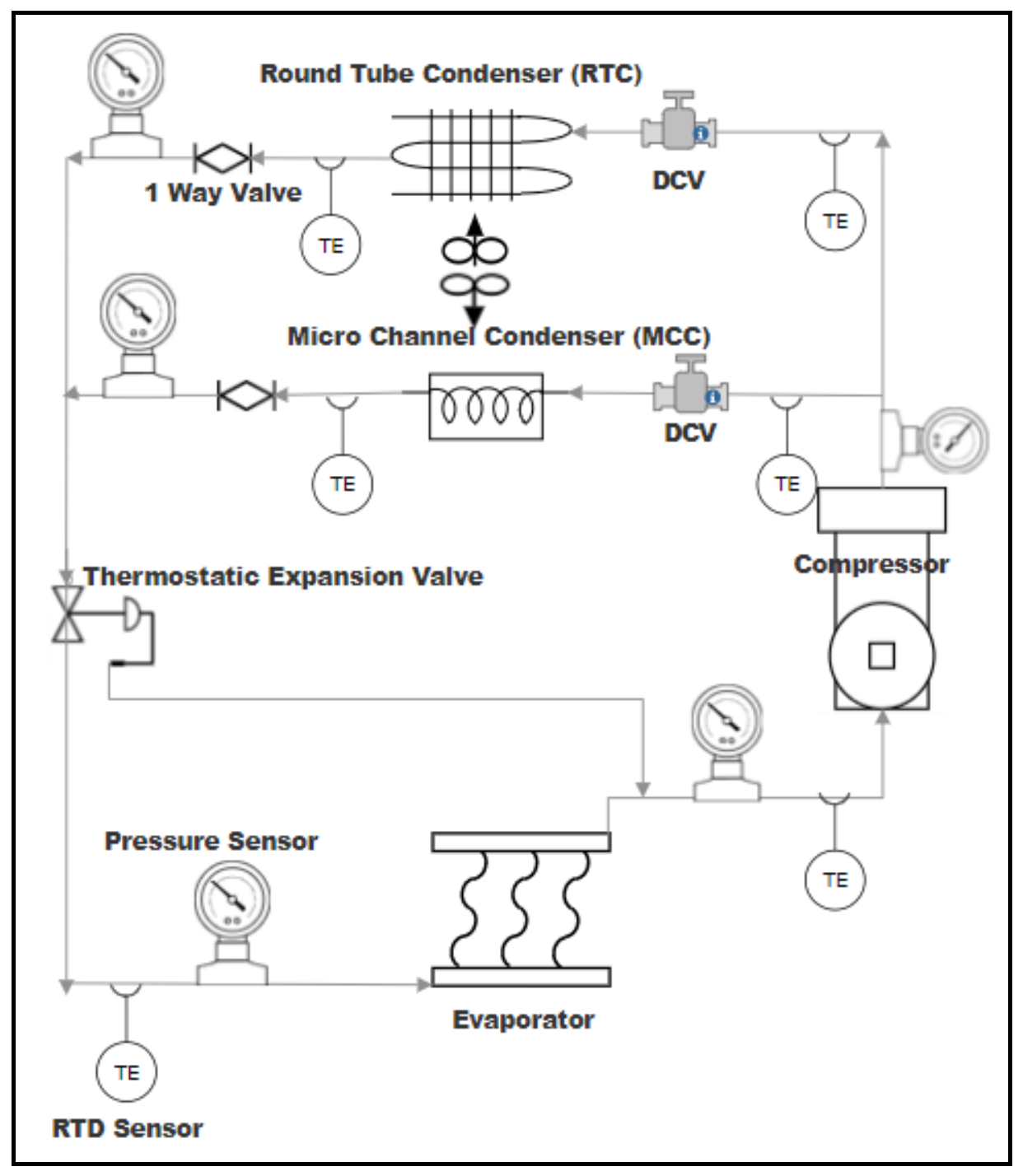

Figure 1. Line diagram of Experimental Setup 
All of the experiments were carried out in environmental chambers using instrumentation that could measure both water and refrigerant parameters. The pressure and temperature of refrigerants at various places were measured to find the thermodynamics properties of the refrigerants using 2RTD sensor, 4 thermocouple sensor and 4 piezoelectric pressure gauges, and our sensors are calibrated in-house using certified references and have an uncertainty of $0.3 \mathrm{~K}$., and there is a 0.1 percent uncertainty in the pressure transducers. A digital wattmeter is used to measure compressor electric consumption, with a proper calibration; it has an uncertainty of $0.5 \%$. REFPROP is used to calculate the thermodynamic characteristics.

The studies were carried out with different combination of condenser and refrigerants i.e normal condenser, Micro channel condenser, R134a and R1234yf. The final findings for each test condition were achieved at $20^{\circ} \mathrm{C}, 15^{\circ} \mathrm{C}, 10^{\circ} \mathrm{C}$, and $5^{\circ} \mathrm{C}$ for evaporator load, $40^{\circ} \mathrm{C}$, $4^{\circ} \mathrm{C}$ and $50^{\circ} \mathrm{C}$ for condenser temperatures.

\section{SYSTEM ANALYSIS}

VCR system was analyzed by performance characteristics, which describes about the alternative to condenser and refrigerants. The first parameter is the refrigeration effect Equation (1), which explains about the quantity of heat removed from the water while giving input energy to the compressor Equation (2) (Taejin Lee et al., 2021, Ganeshkumar et al., 2021, J.M. Belman et al, 2017).

$Q_{\text {eva }}=m_{r}\left(h_{1}-h_{4}\right)$

$P_{\text {com }}=m_{r}\left(h_{2}-h_{1}\right) / \eta_{\text {is }}$

$m_{r}=\frac{V_{s t} * N * \eta_{v o l}}{V_{4}}$

Where, $m_{r}$ represents flow rate of refrigerant Equation (3), $h_{1}$ and $h_{4}$ refers enthalpy of refrigerant at inlet and outlet of evaporator respectively, $\eta_{\text {is }}$ and $\eta_{v o l}$ means the isentropic efficiency and volumetric of the compressor respectively and $h_{2}$ refers to the enthalpy of refrigerants at outlet of compressor. $\mathrm{N}$ is compressor speed and $V_{4}$ is the specific volume of 
the refrigerant at inlet of the compressor.

Coefficient of performance will be calculated based on the Equation (4), which indicates the system performance.

$C O P=\frac{Q_{e v a}}{P_{\text {com }}}$

Equation. (5), (6), (7) and (8) are used to compute the amount of energy destroyed in the compressor $\left(E D_{\text {com }}\right)$, condenser $\left(E D_{\text {con }}\right)$, throttle valve $\left(E D_{\text {tev }}\right)$, and evaporator $\left(E D_{\text {eva }}\right)$ respectively (AlptugYatagan baba, et al., 2015) .

$$
\begin{aligned}
& E D_{\text {com }}=E x_{1}+P_{c o m}-E x_{2} \\
& E D_{\text {con }}=E x_{2}-E x_{3}=m_{r}\left(h_{2}-T_{0} S_{2}\right)-m_{r}\left(h_{3}-T_{0} S_{3}\right) \\
& E D_{\text {tev }}=E x_{3}-E x_{3}=m_{r}\left(h_{3}-T_{0} S_{3}\right)-m_{r}\left(h_{4}-T_{0} S_{4}\right)=m_{r}\left\{T_{0}\left(S_{4}-S_{3}\right)\right\} \\
& E D_{\text {eva }}=E x_{4}+Q_{\text {eva }}\left(1-\frac{T_{0}}{T_{r}}\right)-E x_{4}=Q_{\text {eva }}\left(1-\frac{T_{0}}{T_{r}}\right)
\end{aligned}
$$

Where $S_{1}, S_{2}, S_{3}$ and $S_{4}$ are entropies of refrigerant at inlet and outlet of compressor and evaporator respectively. $E x_{1}, E x_{2} . E x_{3}$, and $E x_{4}$ are exergy in compressor, condenser, throttle valve, and evaporator respectively. $T_{0}$ and $T_{r}$ are temperature of ambient and refrigerant respectively. Total Exergy destruction in the VCR system is indicated by equation (9).

$\Sigma E D_{i}=E D_{c o m}+E D_{c o n}+E D_{\text {tev }}+E D_{\text {eva }}$

The rate of thermal exergy loss in a component is calculated as following Equation (10) and (11), (Cleison Henrique de Paula et al., 2020)

$$
E L_{i}=Q_{i}\left(1-\frac{T_{0}}{T_{i}}\right)
$$

Where $Q_{i}$ denotes the heat rejected by that of the ith element and $T_{i}$ denotes the temperature by that of the ith component's state line.

$$
E L_{i}+E D_{i}=\sum(\text { mex })_{\text {in }}-\sum(\text { mex })_{o u t}+\left\{\sum Q_{i}\left(1-\frac{T_{0}}{T_{i}}\right)_{i n}\right\}+\sum P
$$


The ratio between the exergy rate of the product and the exergy rate of the fuel is known as exergetic efficiency. It is indicated by Equation (12).

$\eta_{\text {ex }}=\frac{\mid Q_{i\left(1-\frac{T_{0}}{T_{i}}\right) \mid}}{P_{\text {com }}}$

Exergetic destruction ratio (EDR) is the ratio of total system exergy destruction to product exergy, it is shown in Equation (13) (Honghyun Cho et al., 2016).

$E D R=\frac{E D_{\text {total }}}{E P}=\frac{1}{\eta_{e x}}-1$

The ratio of the destructed exergy inflow to the exergy input required to maintain the process is known as the efficiency deficiency and it is given by Equation (14).

$\delta_{i}=\frac{\sum E L_{i}+\sum E D_{i}}{P \operatorname{Pcom}}$

Where, i stand for exergy loss and destruction at specific components.

\section{RESULT AND DISCUSSION}

The explanation of the computed Refrigeration effect, power consumption, COP and Exergy destruction, and efficiency defect is shown numerically in the following paragraphs.

\section{Performance Analysis:}

Figure 2 depicts the refrigeration effect, COP versus temperature of evaporator for Round tube condenser (RTC) and micro channel condenser (MCC) at a $40^{\circ} \mathrm{C}$ condenser temperature with R134a and R1234fy. Both refrigerants' cooling capacity increases as the evaporator temperature rises. As the flow rate of refrigerant is low, a higher condenser temperature is cooling less for both refrigerants. 


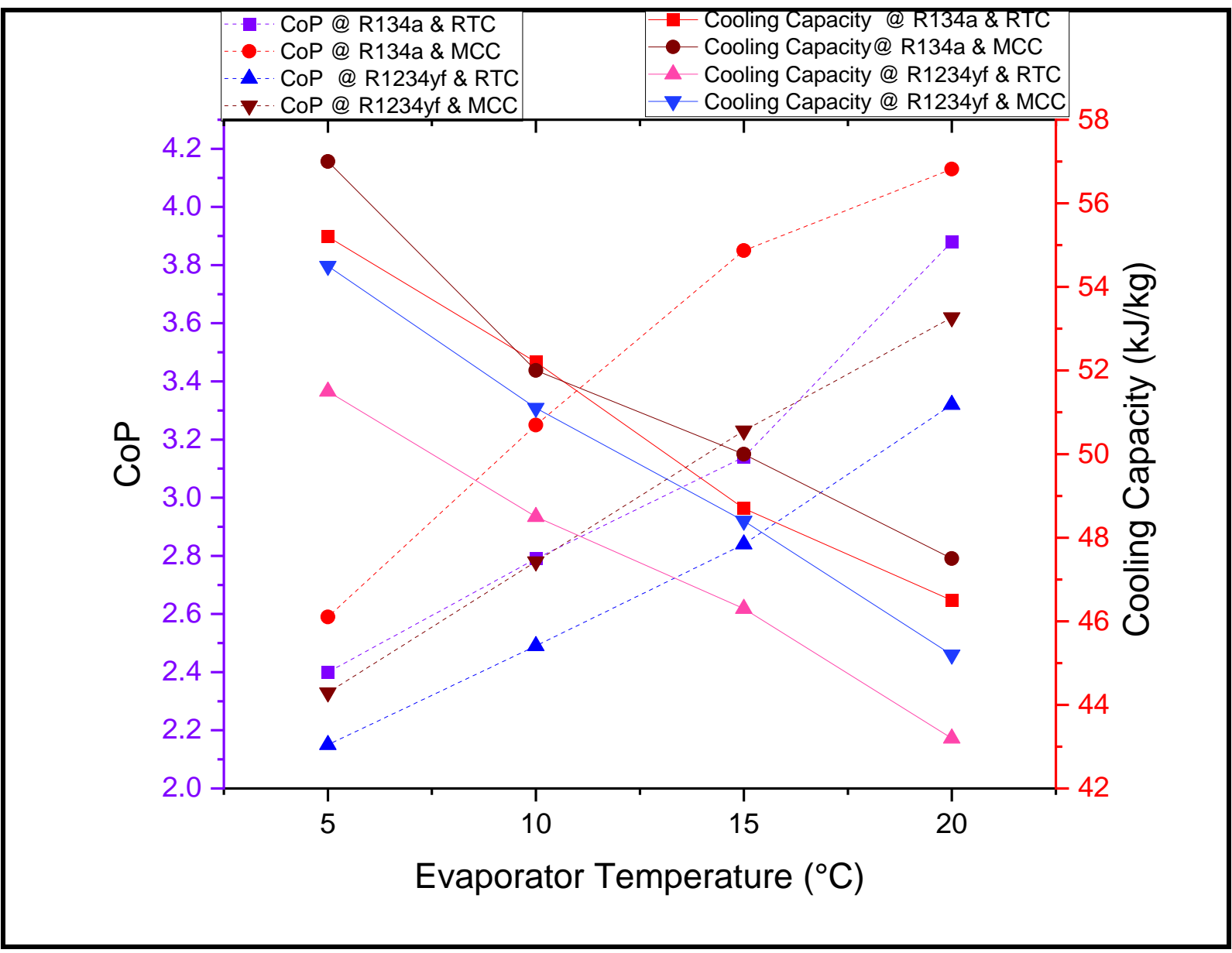

Figure 2. Plot for COP \& Cooling capacity Vs Evaporator Temperature at $40^{\circ} \mathrm{C}$ condenser temperature

R1234yf has a 2-4\% lower cooling capacity than R134a in RTC and 1-2\% lower cooling capacity in MCC. This is due to the fact that R1234yf does have a fairly low latent heat than R134a and MCC has higher Nusselt number than the RTC.R1234yf and R134a have cooling capacities of $51.5 \mathrm{~kJ} / \mathrm{kg}$ and $55.2 \mathrm{~kJ} / \mathrm{kg}$, respectively, at evaporator temperatures of $5^{\circ} \mathrm{C}$ and RTC condenser temperatures of $40^{\circ} \mathrm{C}$. R1234yf and $\mathrm{R} 134 \mathrm{a}$ have cooling capacities of $54.5 \mathrm{~kJ} / \mathrm{kg}$ and $57 \mathrm{~kJ} / \mathrm{kg}$, respectively, at MCC condenser temperatures of $40^{\circ} \mathrm{C}$.If $\mathrm{R} 1234 \mathrm{yf}$ is used in place of R134a in a refrigeration system; this could be a significant change. Hence, instead of RTC, MCC provides better cooling capacity in R1234yf. MCC will be the better option if R1234yf is used as refrigerant because the cooling loss by replacing the R134a in RTC can be overcome by MCC. 
Figure 2 describes that COP rises as evaporator temperature rises for both refrigerants at the MCC and RTC condensers. R1234yf has a lesser COP than R134a in line for the relatively low volumetric efficiency and refrigerating effect. At $5{ }^{\circ} \mathrm{C}$ evaporator and $40{ }^{\circ} \mathrm{C}$ RTC condenser temperatures, R1234yf and R134a have COPs of 2.14 and 2.4, respectively. Incase at $40^{\circ} \mathrm{CMCC}$ condenser temperature, R1234yf and R134a have COPs of 2.3 and 2.6 respectively.

$\mathrm{R} 1234 \mathrm{yf}$ and R134a have attained the maximum COPs of 3.6 and 4.13 at $20^{\circ} \mathrm{C}$ evaporator and $40^{\circ} \mathrm{C}$ condenser temperatures, respectively. Figure 4 illustrate the interaction between the refrigeration effect and COP of the system at various evaporator loads.

Figure 3 illustrates capacity of cooling and COP for R134a and R1234yf at different condenser temperature against $5^{\circ} \mathrm{C}$ of evaporator temperature. Refrigerating effect as well as the COP decreased linearly, because the enthalpy decreased between inlet and outlet of evaporator with both the refrigerants while condenser temperature increases. In addition, the rise in power consumption has worsened COP. The R1234yf refrigerating effect and COP are $2-4 \%$ and $8-13 \%$ less than R134a in RTC condenser, while the R1234yf refrigerating effect and COP are1-3\% and 2-8\% lower in MCC condenser.

Figure 4 illustrates the exergy destruction at each component of VCR system. The compressor generates the most exergy destruction, while the evaporator generates the least due to irreversibility in the compression process. There is low amount of exergy destruction in the condenser due to a huge proportion of entropy is developed, and as a result, a larger portion of exergy is devastated. Hence micro channel condenser and R1234yf combinations have $57.7 \%$ higher exergy destructions than the round tube condenser and R134a combination due to more pumping loss occurs in the MCC and consumption of more power by R1234yf to produce the refrigeration effect than the R134a. 


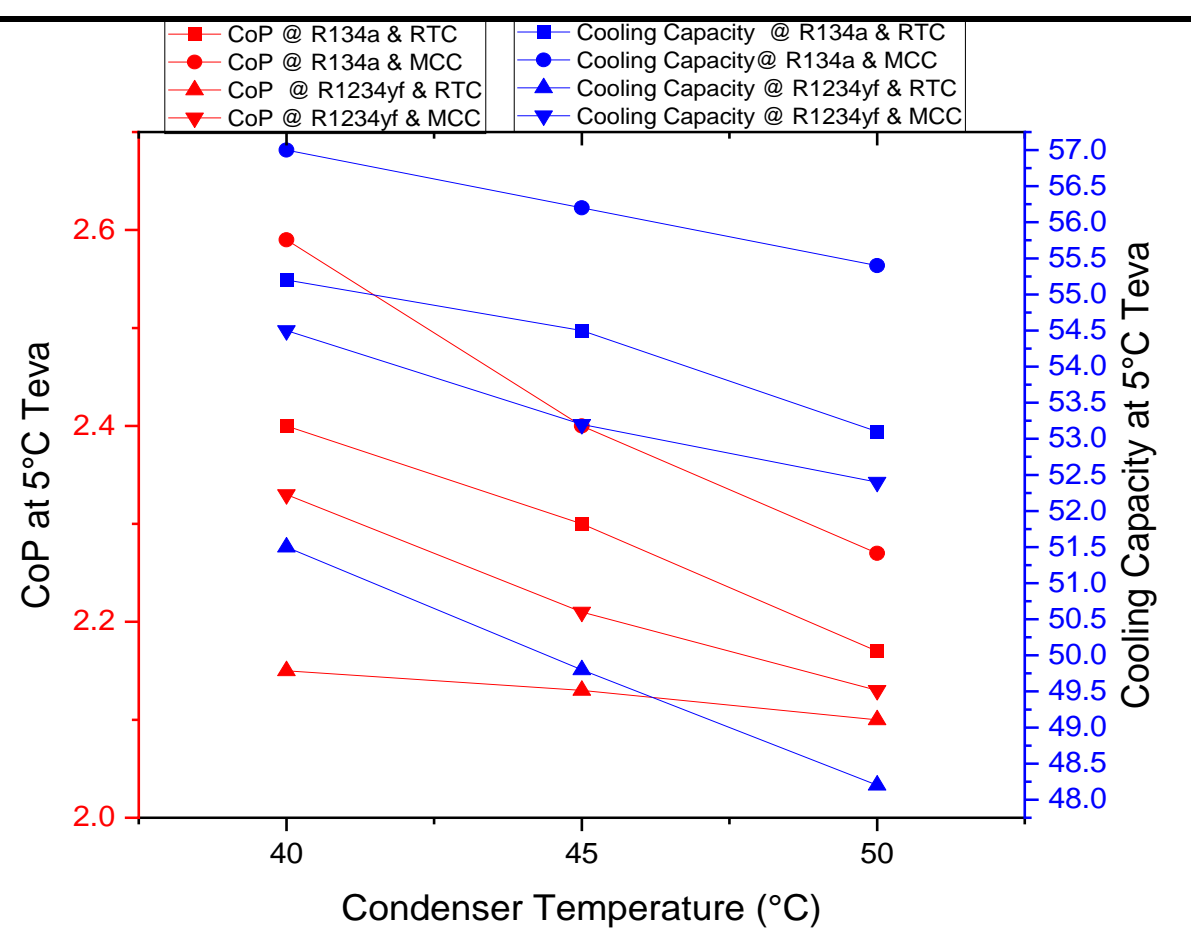

Figure 3. Plot for COP\& Cooling capacity Vs Condenser Temperature at $5^{\circ} \mathrm{C}$ Evaporator

\section{Exergy Analysis:} temperature

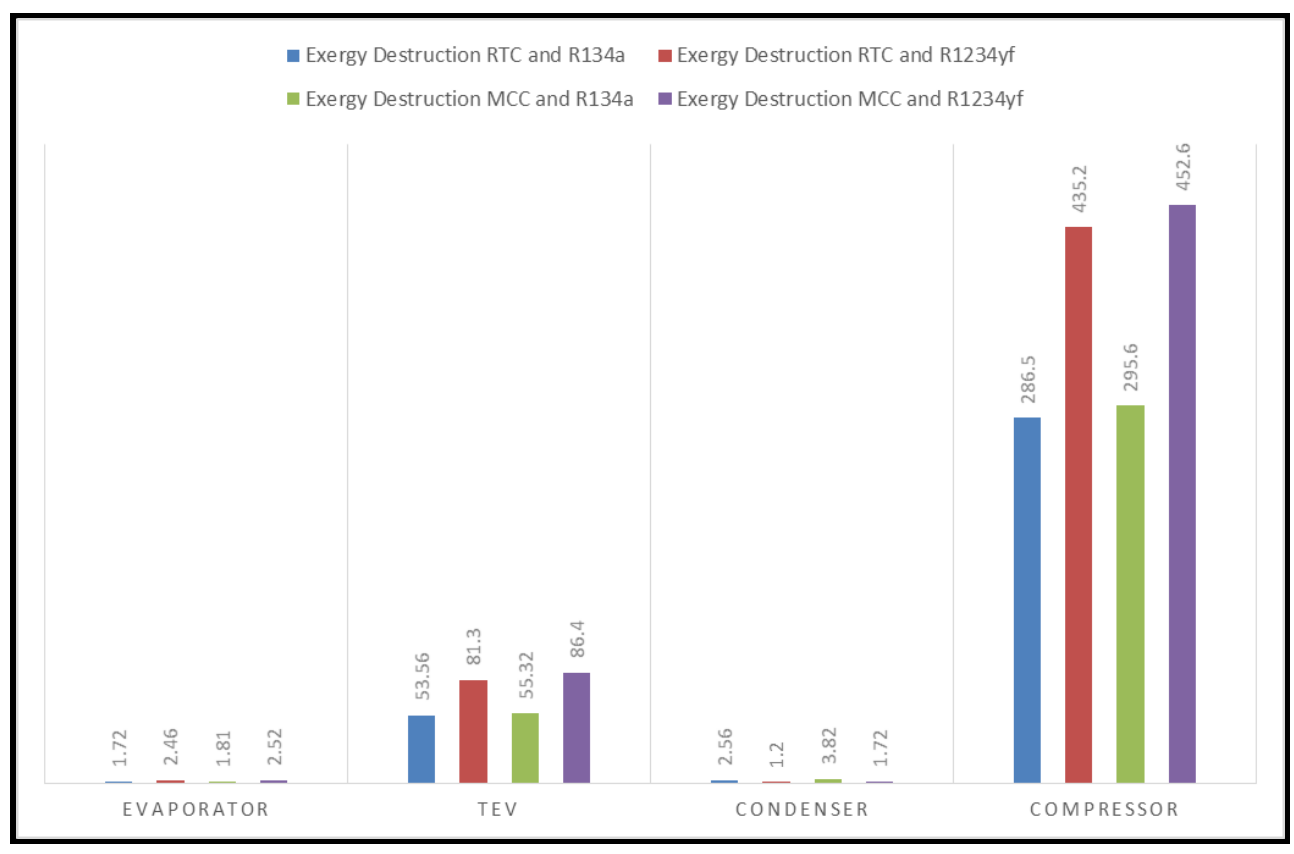

Figure 4. Plot for Exergy destruction Vs VCR components

Figure 5 depicts the exergy efficiency at various evaporator loads and it decreases with increase in the evaporator temperature. The decline and drop in exergetic efficiency as temperature of evaporator increases, is composed of two criteria (refer to Eq. (12)). The very 
first factor is the exergy of cooling effect; as evaporator temperature rises, refrigeration effect rises; moreover, another descriptor $\left(1-\frac{T_{0}}{T_{i}}\right)$ tends to decrease as $T_{r}$ gets closer to dead state temperature; and the operand is compressor work, which lowers as evaporator temperature rises. Two very different refrigeration effect and compressor power do have positive impact on exergetic efficiency, so while decreasing the value of term $\left(1-\frac{T_{0}}{T_{i}}\right)$ has an affirmative influence on exergetic efficiency.

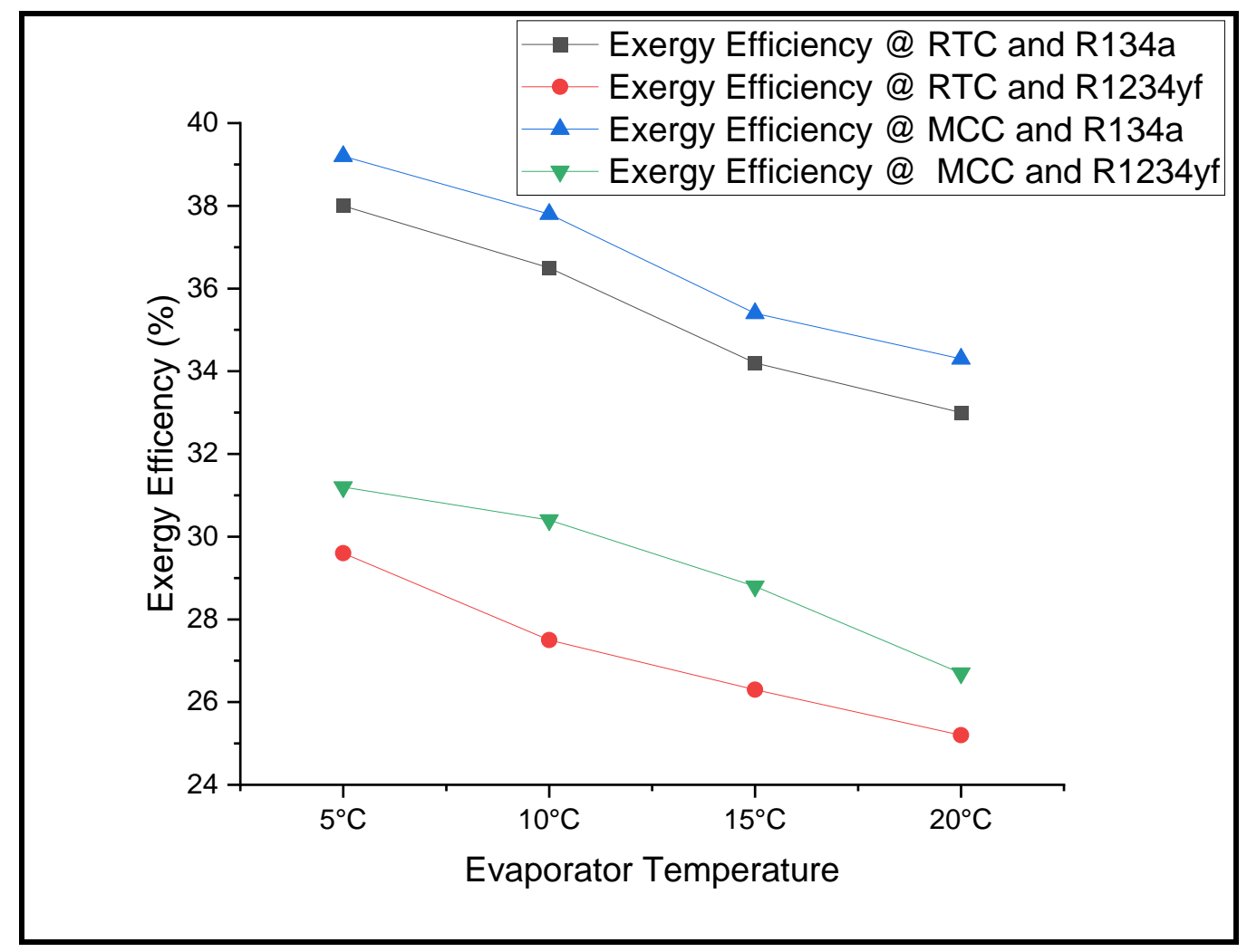

Figure 5. Plot for Exergy efficiency Vs Evaporator Temperature

The consolidated impact of these factors is to significantly boost the exergetic efficiency until the best possible evaporator temperature is attained or approached. Beyond the best possible evaporator and condenser, the cumulative effect of these parameters begins to reduce the exergetic efficiency. Exergy efficiency of MCC condenser and R1234yf has $5.45 \%$ higher than the RTC condenser and R1234yf combinations at the evaporator temperature of $5^{\circ} \mathrm{C}$. 
Figure 6 depicts the impact of evaporator temperature on EDR and efficiency defect. The patterns of the graphs of efficiency defect and EDR have been almost overturned. As the cooling coil heat increases from $5^{\circ} \mathrm{C}$ to $20^{\circ} \mathrm{C}$, the EDR rises as like efficiency defect. At $40^{\circ} \mathrm{C}$ condenser temperature, RTC and R1234yf have a $9.59 \%$ higher exergetic destruction ratio and $5.5 \%$ lower efficiency defect than $\mathrm{MCC}$ and $\mathrm{R} 1234 \mathrm{yf}$ at $40^{\circ} \mathrm{C}$ condenser.

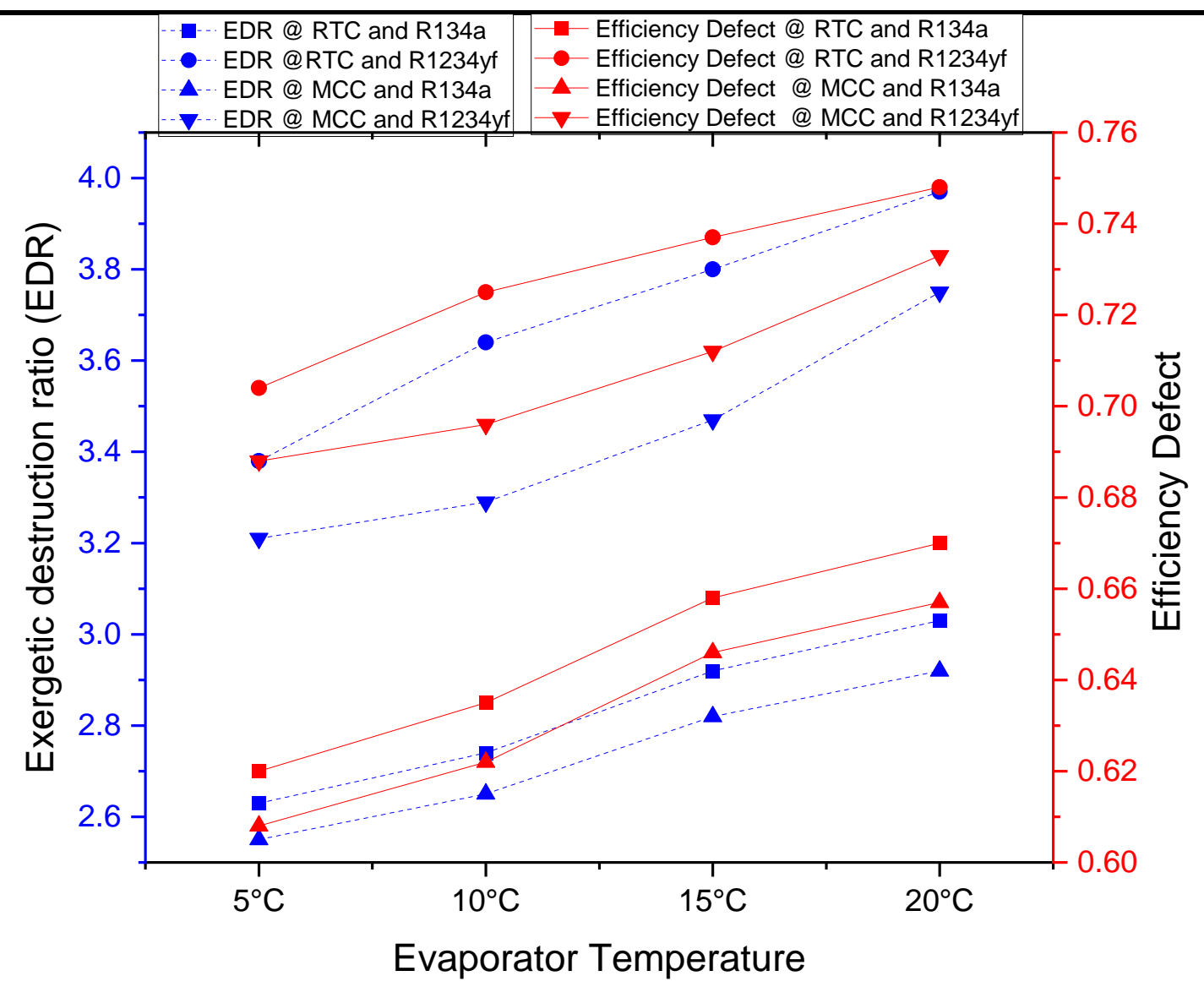

Figure 6. Plot for Exergy destruction ratio, Efficiency defect Vs Evaporator Temperature 


\section{CONCLUSION}

HFO-1234yf and HFC-134a were used in the experiments, which were carried out on a VCR system with a round tube and micro channel condenser. The following conclusions are drawn from the experimental findings:

1) Cooling capacity and COP of VCR system with microchannel condenser and R1234yf are $2.31 \%$ and $0.5 \%$ are lower than the Cooling capacity and COP of VCR system with round tube condenser and R134a. Hence HFO-1234yf performs equal to the HFC-134a while replacing $\mathrm{RTC}$ with $\mathrm{MCC}$.

2) The HFO-1234yf discharge temperature and pressure ratio are below HFC-134a which allow the compressor to work for longer.

3) Exergy efficiency of Micro Channel Condenser and R1234yf has 5.45\% higher than the Round Tube Condenser and R1234yf combinations at the evaporator temperature of $5^{\circ} \mathrm{C}$. 


\section{REFERENCES}

Juan J.G. Pabon, Ali Khosravi, J.M. Belman-Flores, Luiz Machado, Remi Revellin,2020, Applications of refrigerant R1234yf in heating, air conditioning and refrigeration systems: A decade of researches, International Journal of Refrigeration, 118.

Meng Yang, Hua Zhang, ZhaofengMeng, Yanbin Qin, 2019, Experimental study on R1234yf/R134a mixture (R513A) as R134a replacement in a domestic refrigerator,Applied Thermal Engineering,146,540-547, 104-113.

García-Pabón, Juan J., Dario Méndez-Méndez, Juan M. Belman-Flores, Juan M. Barroso-Maldonado, and Ali Khosravi. 2021. "A Review of Recent Research on the Use of R1234yf as an Environmentally Friendly Fluid in the Organic Rankine Cycle" Sustainability 13 , no. 11: 5864 .

Gaurav, Raj Kumar,2018,Computational energy and exergy analysis of R134a, R1234yf, R1234ze and their mixtures in vapour compression system,Ain Shams Engineering Journal, Volume 9, Issue 4, 3229-3237.

Akasaka, R., Tanaka, K., Higashi, Y., 2010. Thermodynamic property modeling for 2,3,3,3 tetrafluoropropene (HFO1234yf). International Journal of Refrigeration, 33, 52-60.

Lee, Y., Jung, D., 2012. A brief performance comparison of R1234yf and R134a in a bench tester for automobile applications. Appl. Therm. Eng. 35, 240-242.

Zilio, C., Brown, J.S., Schiochet, G., Cavallini, A., 2011. The refrigerant R1234yf in air conditioning systems. Energy 36,6110-6120.

Bryson, M., Dixon, C., St Hill, S., 2011. Testing of HFO-1234yf and R152a as mobile air conditioning refrigerant replacements. Ecolibrium, 30-38.

Reasor, P., Aute, V., Radermacher, R., 2010. Refrigerant R1234yf performance comparison investigation. In: International Refrigeration and AirConditioning, Conference. at Purdue, West Lafayette, IN, USA. Paper No.1085.

Leck, T.J., 2010. New high performance, low GWP refrigerants for stationary AC and refrigeration. In: International Refrigeration and AirConditioningConference at Purdue. 
W Lee, Y., Jung, D., 2012. A brief performance comparison of R1234yf and R134a in a bench tester for automobile applications. Applied Thermal Engineering. 35, 240-242.

Endoh, K., Matsushima, H., Takaku, S., 2010. Evaluation of cycle performance of room air conditioner using HFO1234yf as refrigerant, International Refrigeration and Air Conditioning Conference. at Purdue, WestLafayette, IN, USA. Paper No. 1050.

Molés, F., Navarro-Esbrí, J., Peris, B., Mota-Babiloni, A., Barragán-Cervera, A., 2014. Theoretical energy performance evaluation of different single stage vapour compression refrigeration configurations using R1234yf and R1234ze(E) as workingfluids. International Journal of Refrigeration, 44, 141-150.

Nunes, T.K, Vargas, J.V.C., Ordonez, J.C., Shah, D., Martinho, L.C.S., 2015. Modeling, simulation and optimization of a vapor compression refrigeration system dynamic and steady state response. Applied Energy 158, 540-555.

Yataganbaba, A., Kilicarslan, A., Kurtba ,et al, 2015. Exergy analysis of R1234yf and R1234ze as R134a replacements in a two evaporator vapour compression refrigeration system. International Journal of Refrigeration, 60, 26-37.

Sánchez, D., Cabello, R., Llopis, R., Arauzo, I., Catalán-Gil, J., Torrella, E., 2017. Energy performance evaluation of R1234yf, R1234ze(E), R600a, R290 and R152a as low- GWP R134a alternatives. International Journal of Refrigeration,74, 267-280.

J. Navarro-Esbrí et al., (2013) Experimental analysis of R1234yf as a drop-inreplacement for R134a in a vapor compression system, International Journal of Refrigeration,36 (3), $870-880$.

.Martin RyhlKærn, GennaroCriscuolo, Knud Erik Meyer, Wiebke Brix Markussen,(2021), Critical heat flux characteristics of R1234yf, R1234ze(E) and R134a during saturated flow boiling in narrow high aspect ratio microchannels, International Journal of Heat and Mass Transfer,Volume 180,2021,121840.

Taejin Lee, Kyeong-Ho Shin, Jihyun Kim, Dongsoo Jung, Joo-Hyung Kim, 2021,Design optimization of external variable displacement compressor with R1234yf for vehicle air 
conditioning system,Applied Thermal Engineering,Volume 198,2021,117493.

\section{GaneshkumarPoongavanam, VinothkumarSivalingam, RajendranPrabakaran,} Mohammad Salman, Sung Chul Kim, 2021,Selection of the best refrigerant for replacing R134a in automobile air conditioning system using different MCDM methods: A comparative study,Case Studies in Thermal Engineering,Volume 27, 101344.

J.M. Belman-Flores, V.H. Rangel-Hernández, S. Usón, C. Rubio-Maya,(2017)Energy and exergy analysis of R1234yf as drop-in replacement for R134a in a domestic refrigeration system, Energy,Volume 132,Pages 116-125.

AlptugYataganbaba, Ali Kilicarslan, İrfan Kurtbaş, 2015,Exergy analysis of R1234yf and R1234ze as R134a replacements in a two evaporator vapour compression refrigeration system,International Journal of Refrigeration, Volume 60,2015,Pages 26-37.

Cleison Henrique de Paula, Willian Moreira Duarte, Thiago Torres Martins Rocha, Raphael Nunes de Oliveira, Antônio Augusto Torres Maia, (2020),Optimal design and environmental, energy and exergy analysis of a vapor compression refrigeration system using R290, R1234yf, and R744 as alternatives to replace R134a,International Journal of Refrigeration,Volume 113,Pages 10-20.

Honghyun Cho, Chasik Park, (2016), Experimental investigation of performance and exergy analysis of automotive air conditioning systems using refrigerant R1234yf at various compressor speeds,Applied Thermal Engineering,Volume 101,Pages 30-37. 